\title{
Interaction binding study of dimethylamylamine with functional monomers to design a molecular imprinted polymer for doping analysis
}

\author{
Saeful Amin ${ }^{1,2}$, Sophi Damayanti ${ }^{1}$, Slamet Ibrahim ${ }^{1 *}$ \\ ${ }^{1}$ School of Pharmacy, Bandung Institute of Technology, Bandung, Indonesia. \\ ${ }^{2}$ Program Study of Pharmacy, STIKes Bakti Tunas Husada, Tasikmalaya, Indonesia.
}

\begin{tabular}{l}
\hline ARTICLE INFO \\
\hline Received on: $29 / 05 / 2018$ \\
Accepted on: 23/09/2018 \\
Available online: $31 / 10 / 2018$
\end{tabular}

Key words:

DMAA, DFT, hydrogen

bonding, MIPs.

\begin{abstract}
The selection of functional monomers for synthesis of Molecular Imprinting Polymers (MIPs) dimethylamylamine (DMAA) compound had been conducted by non-covalent interaction identification, i.e., hydrogen bonding with DMAA, as the template. The analysis of the template complex was performed by quantum mechanical calculation using B3LYP Density Functional Theory method. The emergence of spontaneous reactions and optimum bond energy indicated the stability of formed MIPs. The results showed the functional monomers, i.e., 2-acrylamide-1-ethanosulfonic acid, itaconic acid, methacrylic acid, acrylic acid, $N$-(2-hydroxyethyl) acrylamide, methyl 6-O-metacryloil- $\alpha$-d-glucoside, and acrylamide could be an option of MIPs synthesis consideration for DMAA with good selectivity.
\end{abstract}

\section{INTRODUCTION}

In sports, supplement becomes one of the athlete's needs to maintain stamina and body health. However, due to the competition in sports events which is getting tighter, some athletes consume not only supplements but also doping in order to increase instant stamina. Doping is a kind of drug which can increase stamina when performing exercise. Because of its nature which forces the body and its negative side effects which can endanger health, doping is prohibited to use (Budiawan, 2013).

Based on the result report of a test conducted by the world anti-doping agency (WADA) (2014), the most common doping category used is the stimulant-type doping of which the most widely used compound in 474 cases is dimethylamylamine (DMAA) in the amount of $16 \%$. This compound is usually contained in energy drinks which are sold as a supplement (Zhang et al., 2012). WADA (2010) put DMAA into the list of drugs or

\section{${ }^{*}$ Corresponding Author}

Slamet Ibrahim, School of Pharmacy, Bandung Institute of Technology, Bandung, Indonesia.E-mail: sibrahim@fa.itb.ac.id doping as a 6.a class substance (Substance.6.a), a non-specific stimulant class. In the following year until 2016, WADA (2016) enlisted DMAA into 6b class substance (Substance 6a), a specific stimulant group. DMAA is associated with various cases of death that occur due to serious side effects it causes. In 2012, the United States Food and Drug Administration stated that DMAA could narrow the blood vessels and arteries which results in the increasing blood pressure and cardiovascular disease (United States Food and Drug Administration, 2012). However, although DMAA has become one of the forbidden doping compounds, a number of athletes are still found using this doping.

To analyze DMAA in a beverage sample, isolation by means of high selectivity extraction needs to be done first. It is performed by using the molecular imprinted polymer (MIP) technique. MIP is an approach for designing artificial receptors which have high recognition of target molecules (Ishak et al., 2015).

To optimize the composition and certain conditions of the MIP synthesis process, computer-aided design (CAD) should be used. Compared with the trial and error method, the computational approach has several advantages such as low price 
and safer and shorter processing time (Pardeshi et al., 2012). In the pre-polymerization stage, CAD approach is used to obtain effective printing by calculating the template and the functional monomer. The results of the CAD approach are essential for MIP preparation to obtain high selectivity (Fu et al., 2015).

In selecting functional monomers of MIP production, the interaction study between template and functional monomers has been successfully applied. The research conducted by Saputra et al. (2013) and Ishak et al. (2015) reported that the success of CAD approach to evaluate the optimum interaction energy in order to select monomers in the production of MIP in case of diazinon and isobutyl nitrate compounds is based on non-covalent interactions.

Interaction study requires many monomers to conduct screening and to choose the easiest, the most effective, and the most economical ones. The monomers used for interaction study between template and functional monomers are monomers which are commonly used for non-covalent printing in MIP production (Lorenzo and Concheiro, 2013).

In this research, the interaction study of DMAA compound with molecular imprinted polymer forming monomers is carried out in order to select effective functional monomers for molecular imprinted polymer synthesis. The results of interaction study with optimum interaction energy are expected to be the theoretical basis in the selection of effective and efficient functional monomers.

\section{RESEARCH METHODS}

\section{Tools and materials}

The tools used in this research were hardware and software. The hardware used was a personal computer with a specification of Intel (R) Core (TM) CPU specifications @ 2.40 $\mathrm{GHz}$, 4,096 MB, Intel HD Graphics Family 3000, 1,460 MB. While the software used was ChemDraw Ultra 3.0, Chem $3 D$ Ultra 3.0, Pyrx-Phyton Prescription 0.8, AutoDockTools 1.5.6rc3, Gaussian 09W Version 8.0, and Gaussian View 5.0.8.

The molecules modeled in this research were DMAA and 33 functional monomers (Lorenzo and Concheiro, 2013).

\section{RESEARCH PROCEDURES}

\section{Hydrogen bond screening}

The production of two-dimensional structure of each template (DMAA) and 33 functional monomers was conducted by using ChemDraw Ultra 3.0. The process was started by minimizing energy (Minimum RMS Gradient 0.010) in Chem3D Ultra 3.0 which was then followed by storing it in .mol 2 file. The screening for hydrogen interactions used Pyrx applications. The interaction results were opened in the AutoDockTools1.5.6rc3 application and the results of nine best positions from Pyrx were viewed based on the interaction along with the bond distance which was formed as the result of hydrogen bond.

\section{Preparation of DMAA and functional monomers}

The drawing of two-dimensional structure of DMAA compounds and functional monomers was conducted manually using ChemDraw Ultra 3.0. It was then stored in .mol2 form in
Chem3D Ultra 3.0. After that, DMAA and functional monomers' files were opened in Gaussian view 5.0.8. Optimization and frequency calculation (Opt + freq) were carried out using B3LYP density functional theory (DFT) method with 6-311G basis set and Gaussian 09W Version 8.0. The result of the preparation was stored in .gjf file and the result of the analysis was stored in .chk file.

\section{Complex compound preparation and calculation}

The results from each DMAA and SYBYL.mol2-shaped monomers were opened in Gaussian view 5.0.8, and then the complex was made manually in one screen through hydrogen bond where the screening results have predicted. After that, complex conducted optimization and frequency calculation (Opt + freq) using B3LYP DFT method with 6-311G basis set and Gaussian $09 \mathrm{~W}$ Version 8.0. The result of the preparation was then stored as a .gjf file and the result of the analysis was stored as .chk file.

\section{Calculation}

From the results of computational calculation on each template, selected functional monomers and complex, binding energy was calculated using the equation (Saputra, 2013):

$$
\Delta E=E_{\text {complex }}-\left(E_{\text {template }}+E_{\text {Functional monomer }}\right)
$$

Then, Gibbs free energy was calculated by using the equation (Sinko, 2012):

$$
\begin{aligned}
& \Delta G=\Delta H-(T \times \Delta S) \\
& \Delta H=H_{\text {complex }}-\left(H_{\text {template }}+H_{\text {monomer }}\right) \\
& \Delta S=S_{\text {complex }}-\left(S_{\text {template }}+S_{\text {monomer }}\right) \\
& T=298.15^{\circ} \mathrm{K} .
\end{aligned}
$$

Furthermore, the complex equilibrium formed was calculated using this equation (Sinko, 2012):

$$
\begin{aligned}
& \Delta G=-\mathrm{RT} \ln K \\
& R=\text { ideal gas constants }\left(8,314 \mathrm{~J} / \mathrm{mol}^{\circ} \mathrm{K}\right) \\
& T=\text { temperature }\left({ }^{\circ} \mathrm{K}\right) \\
& K=\text { equilibrium constant. }
\end{aligned}
$$

From the value of Gibbs free energy obtained and its equilibrium, analysis was performed to obtain an appropriate functional monomer in MIP synthesis for DMAA.

\section{RESULTS AND DISCUSSION}

The functional monomer was an essential material required in the production of MIP because it was responsible for binding the targeted molecule in the cavity. At the time when MIP synthesis was performed, the chain of monomer vinyl experienced addition reactions with the addition of the initiator, and the polymerization reaction was then connected due to crosslinker added (Tahir et al, 2012a).

In MIP with non-covalent formation, the functional monomer used should correspond to the acidity of the template, namely by using the opposite monomer of the template (Lorenzo 
and Concherio, 2013). In its structure, DMAA compound contained $\mathrm{N}$ atoms which had electron-free which can be donated. Hence, according to Lewis theory, DMAA compound was more alkaline.

\section{Hydrogen interaction screening}

Before obtaining the preferred monomer results in the production of MIP of DMAA compound, screening was first performed as an initial stage of functional monomers selection based on hydrogen bonds which were formed in silico with DMAA. Each of the template compound and functional monomer was made in two dimensions and the results were then examined to avoid errors in the production of compound structure. The results were converted into three dimensions and geometry optimization was performed to obtain the optimum and minimum three-dimensional energy from each template compound as well as functional monomers. The results of the screening application processing presented the nine best positions along with their visuals in which functional monomers moved its position while the DMAA compound becomes its center.

From 33 functional monomers tested, there were 17 interacting monomers that form hydrogen bond with DMAA in various positions. The results of this interaction found that the affinity of functional monomers had the highest binding with the template. These results were also affected by the steric hindrances possessed by the compound. In the DMAA structure, there were two $\mathrm{H}$ atoms (number 24 and number 25) which were more electropositive, because they were bound to $\mathrm{N}$ atoms that had high electronegativity, so that these two $\mathrm{H}$ atoms had the opportunity to interact to form hydrogen bond.

In the screening results of functional monomers, the $\mathrm{H}$ atom (number 25) attached to the $\mathrm{N}$ atom of DMAA formed a hydrogen interaction with a high electronegativity atom. $\mathrm{H}$ atom (number 25) had a higher probability of interaction than $\mathrm{H}$ atom (number 24). This was influenced by the steric hindrance of $\mathrm{H}$ atom (number 24) and was reinforced by optimization results of DMAA mulliken calculation which indicated that the $\mathrm{H}$ atom (number 25) was more electropositive, with a value of 0.281 , compared to $\mathrm{H}$ atom (number 24) with a mulliken value of 0.280 . $\mathrm{H}$ atom (number 25) which formed hydrogen bond with functional monomers in DMAA structure can be seen in Figure 1.

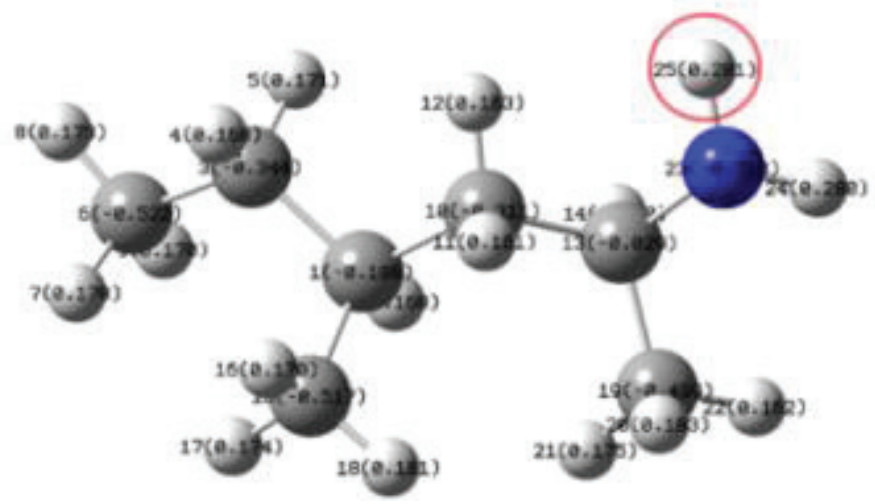

Figure 1. Three-dimensional DMAA structures with its serial numbers of atoms and Mulliken.
The interaction results can be seen using Autodock Tools application that any clusters of functional monomers interacting with DMAA can be seen and the bond distance of the hydrogen bonds can be known.

The hydrogen bond distance between DMAA and 17 functional monomers were ranging from 1.838 to 2.706 Angstroms. The bond distance included a range of moderate-strength hydrogen bond between 1.5 and 2.2 Angstroms and a high-strength between 2.2 and 3.2 Angstrom (Kwan, 2009). These 17 monomers were functional monomers comprising six acidic monomers such as 2-acrylamido-1-ethanesulfonic acid, itaconic acid, methacrylic acid, acrylic acid, 2-(trifluoromethyl)-acrylic acid, and 2-acrylamido-2-methyl-1-propanasulfonic acid, seven neutral monomers such as $\mathrm{N}$-(2-hydroxyethyl), methyl 6-O-methacryloid$\alpha$-D-glucoside, acrylamide, methacrylamide, methyl methacrylate, $\mathrm{N}$-vinyl-2-pyrrolidone, and 2-hydroxyethyl methacrylate, and four basic monomers such as n-(3 methacrylamide), N-(2-aminoethyl) methacrylamide, N-(t-butyl) acrylamide, and N,N,N-trimethyl aminoethyl methacrylate.

\section{Selected template-monomer complex analysis}

\section{Template-monomer preparation result}

From the screening results, the geometry and frequency optimization calculations of the selected functional monomers were performed by using Gaussian09W Software. Geometry optimization was performed to obtain the most stable form of a molecule. Geometry optimization consisted of several repetitions of the calculation of structure parameters and wave functions until the minimum energy was reached. Frequency calculations were performed to obtain the thermal correction value of the total enthalpy energy and the entropy of the system. The enthalpy total energy data with thermal correction as well as the resulting entropy were used to calculate complex Gibbs free energy.

The second total energy data from DMAA template and functional monomers which were calculated using the B3LYP DFT method with 6-311G basis set was used to calculate the DMAA complex binding energy with the functional monomers selected in various positions. The energy produced from the molecule was a function of electron density, where the DFT calculation used the B3LYP function for the correlation-exchange energy, whereas to represent the orbitals occupied by the electrons in the molecule used the basis set.

6-311G basis set which was a triple zeta basis set with a separate set of bases used three basic functions on each atom separated. The $\mathrm{G}$ notation on the basis set showed the type of Gaussian orbital used; 6-311 meant it was using six Gaussian functions representing the core orbital, three Gaussian functions represented each valence atomic orbitals added with a contracted Gaussian function which was denoted by 1 . The high basis set on the 6-311G basis set had a high degree of accuracy to get a more precise total electronic energy value, so the results were expected to be closer to the experiment (Standard, 2015).

Each data from the Gaussian calculation of DMAA compound as the selected template and functional monomers become important data in the calculation which determined the amount of Gibbs free energy and the binding energy in the 
complex. The total energy of DMAA and the selected functional monomers can be seen in Table 2 .

\section{Template-monomer complex result}

Manually, the complex was made from selected functional monomers with DMAA in Gaussian view applications, and the selected set was interacted by hydrogen bond based on preliminary screening data. Complex was formed in the clean automatically to achieve the best shape or position, then the calculation was performed on Gaussian software using the same method and basis set with the calculation of DMAA and functional monomers. The data obtained from the total energy of this complex were reduced by the total energy data of each DMAA and functional monomer that had been calculated on Gaussian, so that the binding energy formed on the complex can be obtained through equation (1).

While, complex Gibbs free energy was obtained through equation (2). In this study, the type of interaction that occurred between the monomers in the complex was the non-covalent interaction of the hydrogen bond. This noncovalent interaction was more widely used because of its advantages, namely that it did not require synthetic steps on the formation of template-functional monomer complex and it was easier in the process of disposing of templates at the washing stage (Riahi et al., 2009). The stable complex was formed into a major consideration in the MIP synthesis so that the complex was indicated to have high intermittent temporal-monomer energy.

The interaction energy can be seen through the binding energy ( $\mathrm{AE}$ ) formed in the complex. This bonding energy was called as the binding force holding unified molecules (intramolecular bonds) or as a binding force maintaining a non-covalent substance by hydrogen bonding (Sinko, 2012). In addition, the parameters that served as the criteria for selecting good functional monomers for the preparation of MIP of DMAA compound can be seen from the Gibbs free energy formed.

Gibbs free $(\Delta G)$ energy produced must be negative to allow the reaction to run spontaneously. This free energy was affected by enthalpy changes and entropy values in the system. In research with computation method, the reaction that happened was done at constant room temperature which was $298.15^{\circ} \mathrm{K}$. Table 1 presents complex interaction energy data with a ratio of 1:1 functional template monomer ratio. The complex values between DMAA and functional monomers in Table 2 are the results drawn from the DMAA complex with functional monomer with the values of Gibbs free energy and the best binding energy at each selected functional monomer position which are based on hydrogen interaction.

Based on these data, the resulting binding energy is about $-3 \sim-27 \mathrm{kcal} / \mathrm{mol}$. While the ideal bonding energy in the hydrogen bond for MIP synthesis is in the range of $-4 \sim-9 \mathrm{kcal} / \mathrm{mol}$ (Tahir et al., 2012b). The functional monomer having this range is methyl methacrylate with number 11 of $-7.96 \mathrm{kcal} / \mathrm{mol}$, n-vinyl-2pyrrolidone with number 12 of $-6.95 \mathrm{kcal} / \mathrm{mol}$, 2-hydroxyethyl methacrylate with number 13 of $-6.13 \mathrm{kcal} / \mathrm{mol}$, n-(3-aminopropyl) methacrylamide with number 14 of $-8.56 \mathrm{kcal} / \mathrm{mol}$, and n-(t-butyl) acrylamide with number 16 of $-6.06 \mathrm{kcal} / \mathrm{mol}$.

Those five functional monomers had met the criteria and had ideal binding energy. However, when viewed from complex Gibbs free energy $(\Delta G)$ produced, those five monomers were positive so they did not react spontaneously or were endothermic, and cannot be used in the MIP-production process for DMAA. The resulting Gibbs free energy value becomes the criteria of functional monomer selection used, since the complex reaction must occur spontaneously and characterized by a negative $\Delta G$ value (Rahayu, 2006).

Table 1. The values of Gibbs free energy $(\Delta G)$ and interaction energy $(\Delta E)$, along with the total energy of template, monomer, and complex template-monomer

\begin{tabular}{|c|c|c|c|c|c|c|}
\hline \multirow{2}{*}{ No } & \multirow{2}{*}{ Functional monomer (the interacted group) } & \multirow{2}{*}{$\begin{array}{c}\Delta G \\
(\mathrm{kcal} / \mathrm{mol})\end{array}$} & \multicolumn{3}{|c|}{ Energy (kcal/mol) } & \multirow{2}{*}{$\Delta \mathbf{E}(\mathrm{kcal} / \mathrm{mol}$} \\
\hline & & & DMAA & Monomer & Complex & \\
\hline 1 & 2-Acrylamido-1-ethanesulfonic acid & -12.06 & & $-595,861.05$ & $-804,050.16$ & -27.37 \\
\hline 2 & Itaconic acid & -11.63 & & $-310,627.91$ & $-518,809.99$ & -20.35 \\
\hline 3 & Methacrylic acid & -5.22 & & $-192,313.06$ & $-400,492.46$ & -17.66 \\
\hline 4 & Acrylic acid & -0.19 & & $-167,641.34$ & $-375,814.44$ & -11.36 \\
\hline 5 & 2-(Trifluoromethyl)-acrylic acid & 1.07 & & $-379,148.40$ & $-587,321.81$ & -11.67 \\
\hline 6 & 2-Acrylamido-2-methyl-1-propanesulfonic acid & 1.49 & & $-645,201.76$ & $-853,373.03$ & -9.53 \\
\hline 7 & $\mathrm{~N}$-(2-hydroxyethyl)acrylamide & -4.71 & & $-251,699.68$ & $-459,878.08$ & -16.66 \\
\hline 8 & Methyl 6-O-methacryloyl- $\alpha$-D-glucoside & -3.86 & & $-575,528.43$ & $-783,706.76$ & -16.59 \\
\hline 9 & Acrylamide & -0.94 & -208161.74 & $-155,175.79$ & $--363,349.93$ & -12.39 \\
\hline 10 & Methacrylamide & 0.49 & & $-179,845.78$ & $-388,017.01$ & -9.49 \\
\hline 11 & Methyl methacrylate & 2.87 & & $-216,973.02$ & $-425,142.72$ & -7.96 \\
\hline 12 & $\mathrm{~N}$-vinyl-2-pyrrolidinone & 4.44 & & $-253,850.47$ & $-462,019.16$ & -6.95 \\
\hline 13 & 2-Hydroxyethyl methacrylate & 6.78 & & $-288,837.38$ & $-497,005.25$ & -6.13 \\
\hline 14 & $\mathrm{~N}$-(3-aminopropyl)methacrylamide & 2.49 & & $-288,577.26$ & $-496,747.56$ & -8.56 \\
\hline 15 & $\mathrm{~N}$-(2-aminoethyl) methacrylamide & 3.35 & & $-263,909.24$ & $-472,081.02$ & -10.04 \\
\hline 16 & $\mathrm{~N}$-(t-butyl)acrylamide & 4.45 & & $-228,422.81$ & $-436,590.60$ & -6.06 \\
\hline 17 & $\mathrm{~N}, \mathrm{~N}, \mathrm{~N}$-trimethylaminoethyl-methacrylate & 7.67 & & $-350,685.40$ & $-558,851.11$ & -3.97 \\
\hline
\end{tabular}


Table 2. The value of Gibbs free energy $(\Delta G)$ and equilibrium constant $(K)$ of DMAA complex with the selected functional monomers.

\begin{tabular}{lcc}
\hline Functional monomer & $\Delta \boldsymbol{G}(\mathbf{k c a l} / \mathbf{m o l})$ & $\boldsymbol{K}$ \\
\hline 2-Acrylamido-1-ethanesulfonic acid & -12.06 & $6.95 \times 10^{8}$ \\
Itaconic acid & -11.63 & $3.37 \times 10^{8}$ \\
Methacrylic acid & -5.22 & $6.72 \times 10^{3}$ \\
Acrylic acid & -0.19 & $1.37 \times 10^{0}$ \\
N-(2-hydroxyethyl)acrylamide & -4.71 & $2.85 \times 10^{3}$ \\
Methyl 6-O-methacryloyl- $\alpha$-D-glucoside & -3.86 & $6.80 \times 10^{2}$ \\
Acrylamide & -0.94 & $4.92 \times 10^{0}$ \\
\hline
\end{tabular}

Table 1 shows that from 17 functional monomers, seven selected eligible monomers for reaction spontaneity are (1) 2-acrylamido-1-ethanesulfonic acid with energy of $-12.06 \mathrm{kcal} / \mathrm{mol},(2)$ itaconic acid with energy of $-11.63 \mathrm{kcal} / \mathrm{mol}$, (3) methacrylic acid with energy of $-5.22 \mathrm{kcal} / \mathrm{mol}$, (4) acrylic acid with energy of $-0.19 \mathrm{kcal} / \mathrm{mol},(5) \mathrm{N}$-(2-hydroxyethyl) acrylamide with energy of $-4.71 \mathrm{kcal} / \mathrm{mol}$, (6) methyl 6-O-methacryloid- $\alpha$-dglucoside with energy of $-3.86 \mathrm{kcal} / \mathrm{mol}$, and (7) acrylamide with energy of $-0.94 \mathrm{kcal} / \mathrm{mol}$. Figure 2 shows a DMAA interaction diagram with seven selected monomers based on the negative value of Gibbs free energy.

From these seven functional monomers, the best monomer which had the smallest Gibbs $(\Delta G)$ free energy value was 2-acrylamido-1-ethanesulfonic acid, where the $\mathrm{S}=\mathrm{O}$ set interacted with the $\mathrm{H}$ atom bound to the N DMAA atom. The smaller the value of Gibbs free energy, the better the complex forming reaction spontaneity. Based on the calculation results using the equation (3), the constant value of equilibrium (K) of the monomer was $6.9 \times 10^{8}$, which was the greatest value among other monomers. A reaction is considered to occur spontaneously if the price of $K>1$, or better if $K>>1$ (Rahayu, 2006). The greater the value of $K$, the higher the spontaneity reaction in the complex. The value of $K$ in the selected complex can be seen in Table 2.

In the complex which was formed, the value of the binding energy $(\Delta E)$ also concerned in choosing functional monomers for MIP of DMAA compound. The 2-acrylamido1-ethane sulfonic acid monomer, in its complex with DMAA, had the smallest binding energy value that marks a very strong bond of $-27.37 \mathrm{kcal} / \mathrm{mol}$. The smaller the value of the binding energy, the stronger the interaction energy and the more stable the complex formed and the better the MIP selectivity for the synthesized DMAA. On the other hand, a very strong interaction made it difficult to leach or discharge the templates to form a DMAA cavity. Extremely strong bonds between the template and functional monomers in MIP required special treatments in the washing process such as using strong solvents in drawing templates, longer discharge processes, and even high heating. However, the washing process still left the residue of the template on the final product of MIP (Saputra et al., 2013). The great binding energy indicated weak interaction and less stable complexes formed, so the resulting MIP had low selectivity to DMAA. The illustration of DMAA interaction with each selected functional monomers can be seen in Figure 3.

Based on the data, these seven functional monomers that react spontaneously can be selected in the production of MIP for DMAA compound. The smaller the Gibbs free energy, the better the reaction process to form the DMAA-functional monomer complex. The parameters of binding energy values are important enough to be considered in non-covalent MIP synthesis.

\section{CONCLUSION}

Based on the criteria of Gibbs free energy and binding energy, which uses the quantitative B3LYP DFT quantum

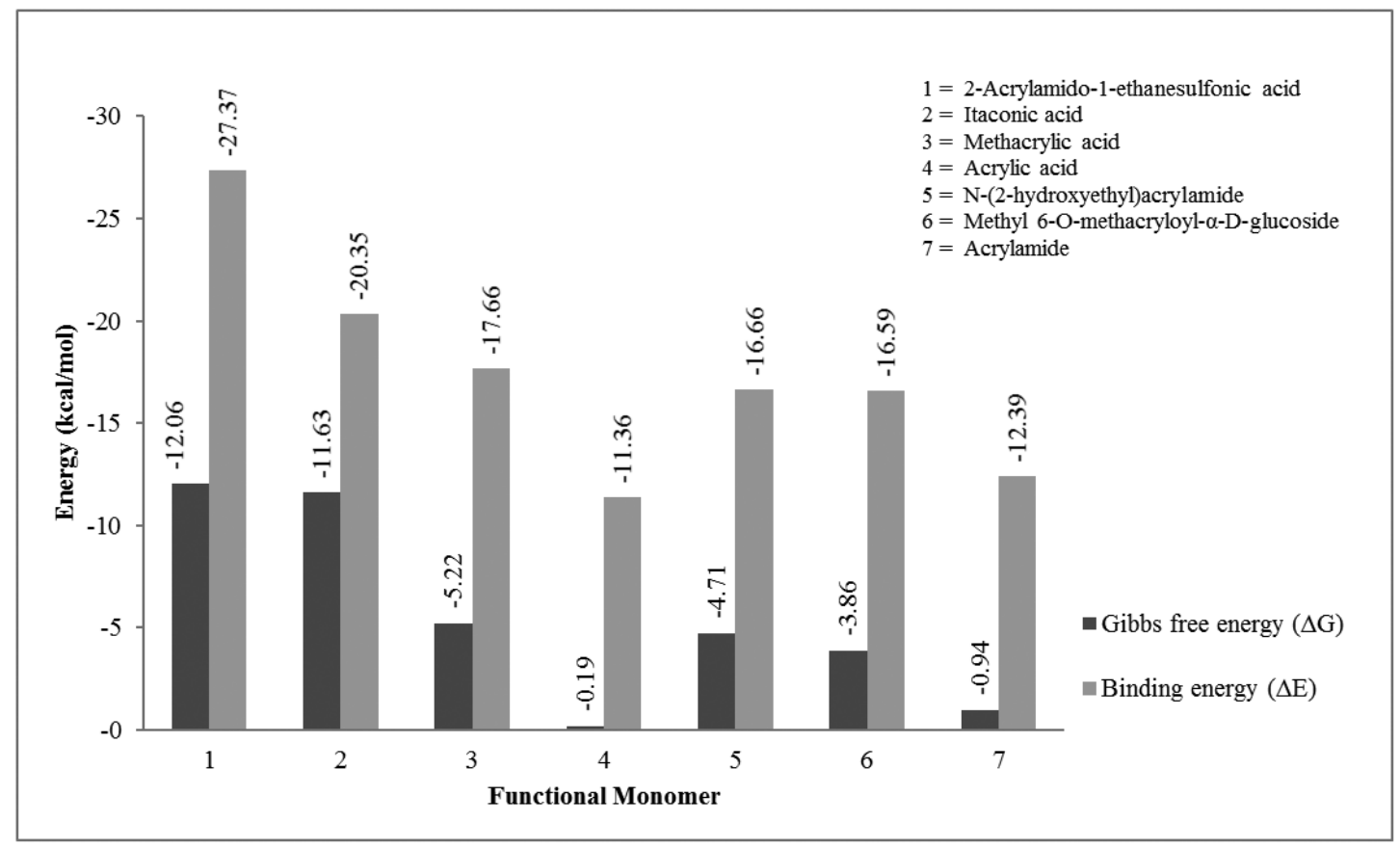

Figure 2. Diagram of the complex interaction-energy on template-functional monomer, selected by Gibbs free energy $(\Delta \mathrm{G})$. 

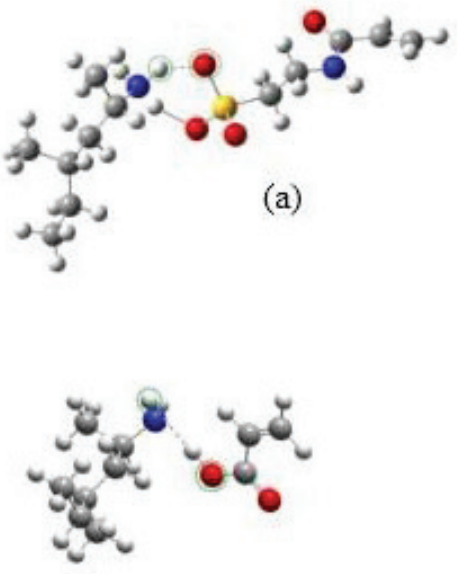

(d)
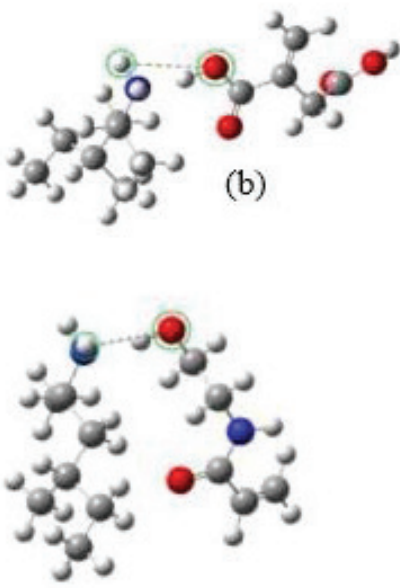

(e)

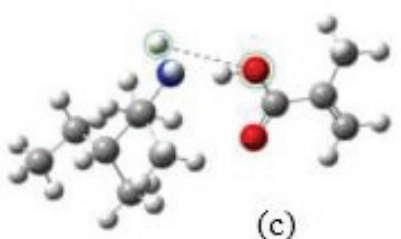

(c)
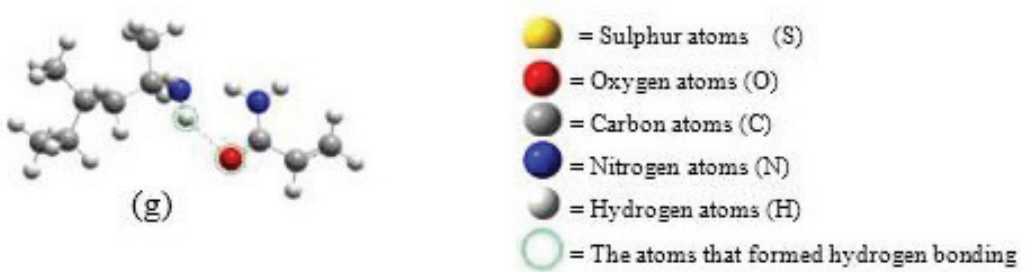

(f)

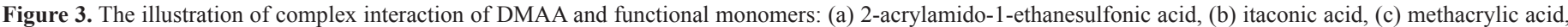
(d) acrylic acid, (e) n-(2- hydroxyethyl) acrylamide, (f) methyl 6-O-methacryloyl- $\alpha$-D-glucoside, and (g) acrylamide.

calculation with a $6-311 \mathrm{G}$ basis set, the selected monomers obtained are 2-acrylamide-1-ethanesulfonic acid $(\Delta G=-12.06 \mathrm{kcal} / \mathrm{mol}$; $\Delta E=-27.37 \mathrm{kcal} / \mathrm{mol})$, itaconic acid $(\Delta G=-11.63 \mathrm{kcal} / \mathrm{mol}$; $\Delta E=-20.35 \mathrm{kcal} / \mathrm{mol})$, methacrylic acid $(\Delta G=-5.22 \mathrm{kcal} \mathrm{mol}$; $\Delta E=-17.66 \mathrm{kcal} / \mathrm{mol})$, acrylic acid $(\Delta G=-0.19 \mathrm{kcal} / \mathrm{mol}$; $\Delta E=-11.36 \mathrm{kcal} / \mathrm{mol}), \mathrm{N}-(2$-hydroxyethyl) acrylamide $(\Delta G=-4.71$ $\mathrm{kcal} / \mathrm{mol} ; \Delta E=-16.66 \mathrm{kcal} / \mathrm{mol})$, methyl 6-O-methacryloid$\alpha$-d-glucoside $(\Delta G=-3.86 \mathrm{kcal} / \mathrm{mol} ; \Delta E=-16.59 \mathrm{kcal} / \mathrm{mol})$, and acrylamide $(\Delta G=-0.94 \mathrm{kcal} / \mathrm{mol} ; \Delta E=-12.39 \mathrm{kcal} / \mathrm{mol})$. Theoretically, these seven functional monomers can be used as good functional monomers for the synthesis of MIP dimethylamylamine compound (DMAA).

\section{ACKNOWLEDGMENTS}

This research was supported by the grant of Scientific Research and Innovation Group, Bandung Institute of Technology.

\section{REFERENCES}

Budiawan M. Doping in sport. Presented on Seminar Nasional FMIPA UNDIKSHA III, Bali, Indonesia, 2013.

Fu X, Yang Q, Zhou Q, Lin Q, Wang C. Template-monomer interaction in molecular imprinting: Is the Strongest the Best? J Organ Poly Mat, 2015; 5:58-68.

Ishak N, Mohd NA, Azalina MN, Shafiqul IAKM. Computational modeling and synthesis of Molecular Imprinted Polymers for recognition of nitrate ion. Malaysian J Anal Sci, 2015; 19(4):866-73.

Kwan EE. An introduction to hydrogen bonding. Presented at An Evans Group Afternoon Seminar. Evans Group, Harvard University, USA, 2009.
Lorenzo, Concheiro. Handbook of molecularly imprinted polymers. Smithers Rapra Group, UK, 2013.

Pardeshi S, Ranjendra P, Rita D, Anupama K. Validation of computational approach to study monomer selectivity toward the template Gallic acid for rational molecularly imprinted polymer design. J Mol Model, 2012; 8:4797-810.

Rahayu. Termodinamika: Asas dasar dan terapan kimia. ITB Bandung, Indonesia, 2006

Riahi S, Tabrizi FS, Javanbakht M, Ganjali MR, Norouzi P. A computational approach to studying functional monomer selectivity towards the template in an imprinted polymer. J Mol Model, 2009; 15:829-36.

Sinko. Martin farmasi fisika dan ilmu farmasetika. EGC, Jakarta, Indonesia, 2012.

Saputra A, Karna W, Mohd NA, Iqmal T. Penggunaan metode semiempirik AM1 untuk pemilihan monomer fungsional efektif pada prasintesis polimer tercetak diazinon. Valensi, 2013; 3(1):1-8.

Standard, Jean M. Basis set notation. Chemistry 2015; 460:1-7.

Tahir I, Mohd NA, Dahyar A. Penggunaan metode semiempirik PM3 untuk evaluasi interaksi allopurinol-asam metakrilat untuk sintesis polimer tercetak molekul. Chem Prog, 2012a; 5(1):11-8.

Tahir I, Mohd NA, Shafiqul IKM, Dahyar A. Pemodel molekul polimer tercetak molekul asam borat untuk aplikasi quartz cristal mikrobalance. J Kimia, 2012b; 6(2):101-9.

United States Food and Drug Administration. FDA challenges marketing of DMAA products for lack of safety evidence. FDA News Release, 2012. [Online]. Available via http://www.fda.gov/NewsEvents/Newsroom/ PressAnnouncements/ucm302133.htm (Accessed 20 February 2016).

WADA. The World Anti-Doping Code The 2010 Prohibited List International Standard. 2010. [Online]. Available via http://wada-mainprod. s3.amazonaws.com/resources/files/WADA_Prohibited_List_2010_EN.pdf (Accessed 20 February 2016). 
WADA. World anti-doping testing figures by Laboratory. World Anti-Doping Agency, New York, NY, 2014.

WADA. World anti-doping Code international standard Prohibited list. World Anti-Doping Agency, New York, NY, 2016.

Zhang Y, Ross MW, Zachary SB, Daniel WA. 1,3-Dimethylamylsamine (DMAA) in supplements and geranium products: natural or synthetic? Drug Test Anal, 2012; 4(12):1-5.
How to cite this article:

Amin S, Damayanti S, Ibrahim S. Interaction binding study of dimethylamylamine with functional monomers to design a molecular imprinted polymer for doping analysis. J App Pharm Sci, 2018; 8(10): 025-031. 